\title{
Spatial-Temporal Characteristics and Determinants of Innovation Output in China
}

\author{
Shujing Guo \\ School College of Economics, Jinan University, Guangzhou, China \\ Email: 13129370126@163.com
}

How to cite this paper: Guo, S.J. (2019) Spatial-Temporal Characteristics and Determinants of Innovation Output in China. Modern Economy, 10, 12-28.

https://doi.org/10.4236/me.2019.101002

Received: December 10, 2018

Accepted: January 7, 2019

Published: January 10, 2019

Copyright $\odot 2019$ by author(s) and Scientific Research Publishing Inc. This work is licensed under the Creative Commons Attribution International License (CC BY 4.0).

http://creativecommons.org/licenses/by/4.0/

\begin{abstract}
Based on the Entropy Method, ESDA and spatial panel data model methods using urban patents database of China's 285 cities during 2014-2015, this article explored the spatial pattern and determinants of innovative output. The results show that: Innovative output shows obvious characteristics of geographical agglomeration and spatial agglomeration. Most cities had strong path dependence and lock-in characteristics, and transition didn't occur. When the inter-city correlation is considered, human capital and industrial base are the major driving forces for boosting innovation output. The input of innovation elements will not only promote the improvement of local innovation ability, but also promote the development of innovation capability in the neighboring cities.
\end{abstract}

\section{Keywords}

Innovation Output, Spatial Autocorrelation, Spatial Spillover Effects, Spatial Dynamic Panel Data

\section{Introduction}

Since Schumpeter [1], a representative of neoclassical economists, put forward that innovation is the core of economic growth, and technological progress as well as technological innovation has received more and more attention and research. The economic development of China has entered a new normal, and the driving role of the traditional development mode is becoming increasingly weak. It must rely on innovation to build the core driving force of economic growth [2]. Since the 18th National Congress, the Party Central Committee has proposed the strategy of innovation-driven development, placing scientific and technological innovation in a crucial position. In order to improve the innovation ability of the region, local governments now provide preferential tax poli- 
cies, talent policies and other support to attract innovative resources and create an active innovation environment. However, with the improvement of network, transportation and other infrastructure, the game between spillover effect and agglomeration effect determines whether innovation resources are concentrated in the region and achieve innovation-driven development. Because of the existence of knowledge spillover effect, the innovation activities of a region benefit from the adjacent innovation agglomeration area [3]. Because of the advantages of geographical location, the innovation ability of this region is superior to that of other regions. The existence of agglomeration effect makes innovative elements accumulate continuously under the effect of centripetal force, which leads to innovation differences and enlarges the trend. Innovation output is the result of innovation input. Innovation output reflects regional differences in innovation ability. It is of great practical significance to comprehensively grasp the spatial evolution of innovation output, explore the spatial distribution of innovation ability and implement innovation development strategy based on differentiation.

At present, there are some limitations in the research of the spatial pattern of innovation output in academic research, such as the research level and the neglect of the innovation content of the three patents. Fan Lina [4] discussed the distribution characteristics of patent applications in 31 provinces and municipalities in China from a spatial perspective, but neglects the spatial correlation when analyzing the influencing factors of innovation capability. Li Zhigang [5] used Provincial patent authorization data to represent innovation output, using spatial analysis method to explore the distribution characteristics of innovation output in China, and through regression analysis to further verify and calculate the strength of spatial correlation. Chen Jing [6] visualized the authorized data of invention patents by using GIS tools, and found that although the gap of innovation ability among regions was further widened, there was a unipolar linear development in the areas where innovation activities were concentrated, and invented Patent, design and utility model patents are used for stepwise screening regression analysis of dependent variables. Wang Chunyang [7] uses ESDA analysis tools to study the spatial and temporal patterns of innovation output based on the patent application authorization of 341 Prefectural Administrative Regions in China. He Shunhui [8] based on the number of patents and papers in 287 prefecture-level cities in China from 2001 to 2014, using the mutation series to get the comprehensive score of innovation to represent the innovation output, and reveals the spatial differentiation characteristics and influencing factors of China's innovation capacity through the spatial cross-section model. These studies provide a new perspective for the pattern and evolution of China's innovation output. The spillover effect of innovation output decreases with the expansion of geographical distance. Spatial spillover often exists in a smaller geographical space. At the same time, the research object is too small to describe the evolution of China's overall innovation output pattern. Therefore, scholars move the research object of innovation output from provincial level to urban level, 
analyze the difference characteristics of national innovation output, and compare the difference of innovation output of cities within provinces.

Based on the premise of describing the evolution of China's overall innovation output pattern and considering the availability of data, this paper uses the patent data of prefecture-level cities to explore the characteristics and influencing factors of China's overall innovation output. However, at present, there is no statistical data of three types of patents of cities. In this paper, we use the Patent Retrieval System of China Intellectual Property Office to query patent application, appearance design and utility model patent data, and use the comprehensive index generated by the entropy method to characterize innovation output. Using the data from 2004 to 2015, this paper explores the dynamic evolution pattern of innovation output in 285 prefecture-level cities in China, explores the influencing factors of innovation output with the help of spatial dynamic panel model, and seeks to optimize the allocation of innovation resources.

\section{Research Methods and Data Sources}

\subsection{Index Selection}

Innovation output and innovation input are two aspects of innovation capability. Because not all regions will be innovation outputs, and innovation input does not represent the level of innovation ability. Agglomeration effect is the agglomeration of economic factors and economic activities within a region driven by a certain relationship. When reaching a certain scale, it will produce greater effect than a single factor, and turn into economic effect or non-economic effect. At the same time, because of the existence of spatial correlation between regions, the effect or results on the surrounding areas will be transformed into spillover effect. Through the game of "spillover effect" and "agglomeration effect", the innovation input can represent the innovation ability of the region by transforming production into new technology, new technology, new product or new service. It is difficult for input indicators to reflect the actual innovation ability of a region. At present, among the output indicators, there is no unified measurement data of innovation output, and in view of the fact that patents can reflect the level of innovation technology to a certain extent and the availability of patent data, the academic circles regard patents as a measurement tool of innovation level. For example, Zhang Yuming [9] studied the spatial distribution characteristics of innovation output in China's inter-provincial patent statistics by using spatial measurement methods such as Moran index. Jiang Tianying [10] used nuclear density estimation and other statistical methods to analyze the spatial differentiation characteristics of innovation output in Zhejiang Province based on the patent authorization of Zhejiang Province from 2006 to 2012. In the past, the total amount of patent application authorization for document use reflects the innovation ability among regions, ignoring the technological innovation level of invention authorization, utility model and design patent. As we all know that patent for invention is a new technical scheme for product, method or 
improvement. And the level of technological innovation of invention patents is the highest, which is more helpful to reflect the actual innovation ability of the region than other patents. The proportion of three patents in the comprehensive score of innovation output should be different. Based on the existing literature and taking full account of three kinds of patent innovation content, this paper uses the entropy method to generate a comprehensive score to characterize the innovation output. Compared with the general total amount of patent application authorization or the amount of invention authorization as the innovation output, it can more truly reflect the national innovation output level.

\subsection{Data Sources}

Based on data availability and uniform caliber, this paper takes 285 prefecture-level cities in China (excluding Taiwan Province, Hong Kong Special Administrative Region and Macao Special Administrative Region) as the research object, covering panel data from 2004 to 2015. Considering that the difference of patent data statistical standards between Hong Kong and Macau in Taiwan may interfere with the generality of the results, the research object of this paper does not include the three areas mentioned above. The data of invention patent, appearance design and utility model patents are all come from the patent search system of the China Intellectual Property Office. The data used to measure the difference of innovation output in Theil index are from the "China Urban Statistics Yearbook" over the years. This paper takes the data of 2003 as the base year, and preprocesses the required data by range standardization.

\subsection{Research Method}

\subsubsection{Entropy Method for Comprehensive Score}

Entropy is a concept used to reflect the uniformity of spatial distribution of energy in physics. With the intersection of disciplines, concepts in physics appear more frequently in economics. Entropy method is an objective evaluation method, which can avoid the influence of subjective factors on the accuracy and accuracy of data.

Firstly, standardize three kinds of patent data.

$$
X_{i j}^{*}=\left(X_{i j}-X_{\min (i)}\right) /\left(X_{\max (i)}-X_{\min (i)}\right)
$$

Among them, $X_{i j}^{*}$ is the standardized value of patent data, $X_{i j}$ is the initial value of patent data, $i$ is the innovation output index, $j$ is the city, $X_{\min (i)}$ and $X_{\max (i)}$ represent the maximum value of the first innovation output index, respectively.

Secondly, the proportion of index value of the $j$ city under the first index is calculated:

$$
Y_{i j}=X_{i j}^{*} / \sum_{i=1}^{m} X_{i j}^{*} \quad\left(0 \leq Y_{i j} \leq 1\right)
$$

Calculating index information entropy e and information effect value $d$

$$
e_{i}=-K \sum_{i=1}^{m} Y_{i j} \ln Y_{i j} \quad(K \text { is constant and equal to } 1 / \ln )
$$




$$
d_{i}=1-e_{j}
$$

The bigger the information utility value $d_{i}$ is, the more important the innovation output index of item $i$ is, the bigger the corresponding weight is.

Calculating the final weight of index $i$ :

$$
w_{i}=d_{i} / \sum_{i=1}^{m} d_{i}
$$

Finally, the weights generated by the entropy method are used to calculate the comprehensive score of innovation output.

$$
\text { pat }_{j}=\sum_{i=1}^{m} X_{i j}^{*} * w_{i}
$$

\subsubsection{Measuring Regional Differences by Theil Index}

In 1967, H. Theil, a famous Dutch economist, first put forward the Theil Index, which is used to measure the income gap between citizens and regions. Because Theil Entropy Index can not only calculate intra-group disparities but also measure inter-group disparities, the application of Theil Entropy Index is becoming more and more widespread with the deepening of interdisciplinary.

$$
T=\sum_{i=1}^{N} \frac{R_{i}}{P} \ln \left(\frac{R_{i}}{P_{i}} \cdot \frac{P}{R}\right)
$$

Among them, $T$ is equal to the difference of total patent output capacity of 285 prefecture-level cities, $N=285, I=1,2,3 \ldots 285, R$ represents the total population of the whole country, $R_{i}$ represents the total population of $\mathrm{i}$ city at the end of the year, $P$ is the total score of innovation output, $P_{i}$ is the comprehensive score of innovation output of I city. According to the principle that the provinces where prefecture-level cities are located determine the regional affiliation of prefecture-level cities, the eastern part of this paper includes Beijing, Tianjin, Hebei, Shandong, Jiangsu, Shanghai, Zhejiang, Fujian, Guangdong and Hainan, totaling 87 prefecture-level cities; the northeastern region includes 34 prefecture-level cities of Heilongjiang, Jilin and Liaoning; and the central region includes Shanxi and Hehei. There are 80 prefecture-level cities in South, Anhui, Hubei, Hunan and Jiangxi, and 84 prefecture-level cities in 11 provinces of Inner Mongolia, Shaanxi, Gansu, Ningxia, Sichuan, Chongqing, Guizhou, Guangxi, Yunnan, Xinjiang and Qinghai. The total difference among the four regions in China is the sum of the intra-regional and inter-regional differences.

$$
T=T_{1}+T_{2}
$$

Among them, $T_{1}$ represents the inner Theil index and $T_{2}$ is the inter-regional Theil index. The specific expressions are as follows:

$$
\begin{gathered}
T_{1}=T_{a}+T_{b}+T_{c}+T_{d} \\
=\sum_{j=1}^{87} \frac{R_{j}}{R_{a}} \ln \left(\frac{R_{j}}{P_{j}} \frac{P_{a}}{R_{a}}\right)+\sum_{k=1}^{34} \frac{R_{k}}{R_{b}} \ln \left(\frac{R_{k}}{P_{k}} \frac{P_{b}}{R_{b}}\right) \\
+\sum_{l=1}^{80} \frac{R_{l}}{R_{c}} \ln \left(\frac{R_{l}}{P_{l}} \frac{P_{c}}{R_{c}}\right)+\sum_{m=1}^{84} \frac{R_{m}}{R_{a}} \ln \left(\frac{R_{m}}{P_{m}} \frac{P_{d}}{R_{d}}\right)
\end{gathered}
$$




$$
T_{2}=\frac{R_{a}}{R} \ln \frac{R_{a}}{P_{a}} \frac{P}{R}+\frac{R_{b}}{R} \ln \frac{R_{b}}{P_{b}} \frac{P}{R}+\frac{R_{c}}{R} \ln \frac{R_{c}}{P_{c}} \frac{P}{R}+\frac{R_{d}}{R} \ln \frac{R_{d}}{P_{d}} \frac{P}{R}
$$

\subsubsection{Measuring Spatial Autocorrelation by Moran Index}

Based on the Queen spatial weight matrix, this paper uses the global Moran' I index to measure the spatial autocorrelation between cities, so as to reflect the similarity of cities with common boundaries or vertices. The expression of global Moran' I index is:

$$
I=\frac{n \sum_{i=1}^{n} \sum_{j=1}^{n}\left(x_{i}-\bar{x}\right)\left(x_{j}-\bar{x}\right)}{\left(\sum_{i=1}^{n} \sum_{j=1}^{n} w_{i j}\right) \sum_{i=1}^{n}\left(x_{i}-\bar{x}\right)}
$$

Among them, $-1 \leq I \leq 1$, the greater the positive correlation between regions, that is, the spatial agglomeration between cities with high innovative output and cities with high innovative output; conversely, the closer to -1 , the greater the negative correlation between regions, that is, the greater the gap between innovative output of cities with high innovative output and that of surrounding cities; and $I=0$, the greater the gap between innovative output of cities with high innovative output and that of surrounding cities. The distribution of output is random.

\subsubsection{Measurement of Spatial Spillover Effect}

LeSage and Pace [11] found that the empirical analysis of spatial spillover effects using point estimation measures in the past will lead to errors in the results, and partial differential is used as the basis for explaining the existence of spatial spillover effects. Taking the spatial Durbin model as an example, its general expression is as follows:

$$
Y_{i t}=\rho W Y_{i t}+\beta X_{i t}+\theta W X_{j t}+\mu_{i}+\lambda_{i}+\varepsilon_{i t}
$$

Then the partial derivative matrix of the expected value of the explanatory variable $X$ corresponding to $Y$ is:

$$
\left[\frac{\partial E(Y)}{\partial x_{1 k}} \cdots \frac{\partial E(Y)}{\partial x_{N k}}\right]=(1-\rho W)^{-1}\left[\begin{array}{cccc}
\beta_{K} & w_{12} \theta_{K} & \cdot & w_{1 N} \theta_{K} \\
w_{21} \theta_{K} & \beta_{K} & \cdot & w_{2 N} \theta_{K} \\
\cdot & \cdot & \cdot & \cdot \\
w_{N 1} \theta_{K} & w_{N 2} \theta_{K} & \cdot & \beta_{K}
\end{array}\right]
$$

The direct effect is the average value of the principal diagonal elements of the partial derivative matrix, the indirect effect is the average value of the non-diagonal elements of the matrix, and the sum of the direct effect and the indirect effect is the total effect. The direct effect in this paper reflects the impact of the input of innovation factors on innovation output in the region. It includes "feedback effect", that is, the influence factors of a city act on the surrounding cities, and at the same time transmit to the role of the city. Indirect effect measures the impact of changes in input factors of innovation output on innovation output in other regions. This paper will report various effects in the empirical part. 


\section{Spatial-Temporal Evolution Patterns of Innovation Output in China}

\subsection{Innovation Output Shows Obvious Zonal Characteristics}

On the whole, although the score of innovation output in the four regions is slightly fluctuating, the level of economic activity has a profound impact on the current situation of innovation output pattern and is changing. It still shows the characteristics of differentiation between strong regions in the East and weak regions in the west. Evolution of innovation output scores in four major areas of China are shown in Table 1. Specifically, the score of innovation output in the eastern, central and western regions increased rapidly, with the growth rate of $113.4 \%$ in the central region in the first place, while the score of innovation output in the Northeast was in a negative growth state. The share of innovation output in China ranged from 9.329 to 15.934 in 2015, with a growth rate of $70.78 \%$. The remarkable improvement of the whole country's innovation ability shows that the innovation ability is in a period of accelerated growth.

Innovation output shows the following characteristics: on the one hand, innovation output is concentrated in a few cities, mainly in the eastern coastal provincial capital cities. The results are shown in Table 2. The results of 2004 show that there are eight cities in the east, five of which are provincial capitals, four in the Pearl River Delta, and only Chongqing and Chengdu in the west. The score of Shanghai's innovation output is much higher than that of Beijing and Shenzhen, which are in the second place and place names respectively. The proportion of innovation output is $10.1 \%$. In 2015, the number of cities in the top 10 of innovation output decreased to 7 in the middle and east, and Xi'an, as the capital of Shaanxi Province, ranked in the top 10. In addition to the four provincial capitals, the cities in the eastern part of the Yangtze River Delta increased by 2, while the cities in the Pearl River Delta decreased to Shenzhen and Guangzhou. Compared with the rankings in 2004 and 2015, the overall ranking of cities in the Yangtze River Delta declined, but the number of cities increased. The top ten western cities are all provincial capitals, especially Xi'an. On the other hand, the top ten cities are mainly concentrated in the eastern region, but the proportion of innovation output score is declining, while the innovation output score is in the process of rapid increase, which indicates that the innovation output of

Table 1. Evolution of innovation output scores in four major areas of China.

\begin{tabular}{cccccc}
\hline \multirow{2}{*}{ Region } & \multicolumn{2}{c}{2004} & \multicolumn{2}{c}{2015} & Scoring growth \\
\cline { 2 - 5 } & Score & Ratio & Score & Ratio & \\
\hline East & 6.580 & 0.705 & 11.177 & 0.701 & 0.699 \\
Northeast & 0.587 & 0.063 & 0.420 & 0.026 & -0.283 \\
Central & 0.982 & 0.105 & 2.095 & 0.131 & 1.134 \\
West & 1.181 & 0.127 & 2.242 & 0.141 & 0.898 \\
Total & 9.329 & 1 & 15.934 & 1 & 0.708 \\
\hline
\end{tabular}


Table 2. Top 10 prefecture-level cities with innovation output in China.

\begin{tabular}{ccccccc}
\hline & & 2004 & & & 2015 & \\
\cline { 2 - 6 } & City & Score & Ratio & City & Score & Ratio \\
\hline 1 & Shanghai & 0.941 & 0.101 & Beijing & 0.869 & 0.055 \\
2 & Beijing & 0.769 & 0.082 & Shenzhen & 0.728 & 0.046 \\
3 & Shenzhen & 0.746 & 0.080 & Suzhou & 0.589 & 0.037 \\
4 & Foshan & 0.463 & 0.050 & Shanghai & 0.584 & 0.037 \\
5 & Guangzhou & 0.391 & 0.042 & Chengdu & 0.481 & 0.030 \\
6 & Tianjin & 0.277 & 0.030 & Chonqing & 0.466 & 0.029 \\
7 & Chongqing & 0.271 & 0.029 & Guangzhou & 0.459 & 0.029 \\
8 & Hangzhou & 0.237 & 0.025 & Xian & 0.441 & 0.028 \\
9 & Dongguan & 0.215 & 0.023 & Hangzhou & 0.432 & 0.027 \\
10 & Chengdu & 0.190 & 0.020 & Ningbo & 0.420 & 0.026 \\
& Overall & 9.329 & 1 & Overalll & 15.934 & 1 \\
\hline
\end{tabular}

the whole country is developing from polarization to equilibrium. These regions have diversified industrial structure and abundant human capital conditions, and become the highland of attracting innovative activities. At the same time, the eastern coastal cities and provincial capitals are often the places where scientific research institutes are concentrated and have strong basic scientific research strength. In the meanwhile, mature industrial chain will accelerate the emergence of patents and put them into use.

\subsection{Spatial-Temporal Evolution of Regional Differences in Innovation Output}

The Theil index and Gini coefficient can be used to measure inter-regional differences. The Intyre index has the advantage of quantifying inter-regional and intra-regional differences. In this paper, the Theil index is used to measure the change of regional differences. The Theil index shows a trend of steady fluctuation first and then obvious decline. Since 2010, the Theil index has declined significantly, which indicates that innovation output has developed from polarization to equilibrium diffusion. The regional differences are basically in a stable state with little change. According to Figure 1, we find that the regional differences in 2004-2015 are very close to the total differences, and show a high level. The contribution rate of regional differences to the total differences has been above $88 \%$ by calculating the original data. Although the Theil index in the West shows a downward trend, it has always been the region with the highest Theil index, and the contribution rate to the regional differences is over $33 \%$. The difference of innovation output mainly lies in the regional differences, among which the difference in the west is obvious, which shows that the innovation output in the west is highly concentrated in a few provincial capitals. The regional differences in Northeast China have always been at a low level, and have 


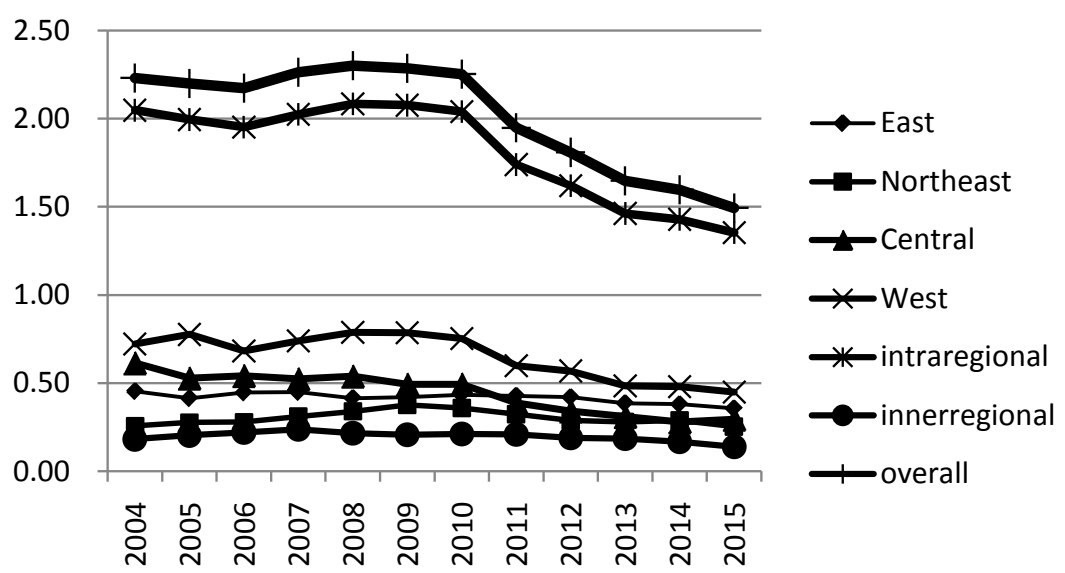

Figure 1. Changes of Theil index of innovation output of prefectural cities in China from 2004 to 2015.

experienced an inverted U-shaped change trend of rising first and then falling. The downward trend in the central region clearly shows that the innovation output is developing in the direction of optimizing and balancing. The internal differences of the eastern regions where innovation output is concentrated are extremely stable, and the innovation capacity and innovation output changes among cities are relatively coordinated.

\subsection{Spatial Autocorrelation of Innovation Output}

This paper uses Geoda to get the Moran index of innovation output of prefecture-level cities in China from 2004 to 2015. The results are shown in Table 3. The study finds that the Moran index has passed 1\% significance level test, and all positive values have obvious positive spillover effect. The increase of Moran index from 2004 to 2015 shows that the spatial correlation of innovation output and innovation ability of prefecture-level cities in China has been improved, and has a high degree of agglomeration effect and self-strengthening momentum. As a whole, the cities with high innovation output are surrounded by the cities with high innovation output, while the cities with low innovation output are surrounded by the cities with low innovation output.

In order to characterize the spatial and temporal differentiation of innovation output in some regions and cities, this paper classifies and adjusts the urban distribution of Moran scatter map based on the cross-sectional data of 2004 and 2015. The urban changes are divided into four categories. I is the change of itself while the surrounding cities remain unchanged; II is the change of itself and the surrounding cities; III is the change of itself and the surrounding cities; IV is that neither of them has changed. At the same time, according to the direction of change, the four categories will be divided into 16 categories, specifically: I: HL-LL ${ }_{t+1}$, LH-HH ${ }_{t+1}$, LL-HL $t_{t+1}, H H-L_{t+1}$; II: HH-LL $L_{t+1}$, LH-HL ${ }_{t+1}, H L-L_{t+1}$,

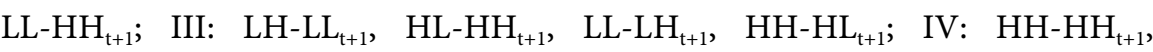
$\mathrm{LH}-\mathrm{LH}_{\mathrm{t}+1}, \mathrm{LL}_{-} \mathrm{LL}_{\mathrm{t}+1}, \mathrm{HL}-\mathrm{HL}_{\mathrm{t}+1}$. Cities not listed in the table fall into category IV.

The results in Table 4 show that most of the cities in or around prefecture-level 
Table 3. Moran's I change of innovation output of prefecture-level cities in China, 2004-2015.

\begin{tabular}{cccccccccc}
\hline Year & Moran's I & sd & $Z$ & $p$ & Year & Moran's I & sd & $Z$ & $p$ \\
\hline 2004 & 0.108 & 0.035 & 3.267 & 0.015 & 2010 & 0.296 & 0.037 & 8.132 & 0.002 \\
2005 & 0.113 & 0.036 & 3.211 & 0.012 & 2011 & 0.308 & 0.036 & 8.581 & 0.001 \\
2006 & 0.110 & 0.032 & 3.550 & 0.009 & 2012 & 0.314 & 0.036 & 8.930 & 0.001 \\
2007 & 0.150 & 0.033 & 4.612 & 0.002 & 2013 & 0.318 & 0.039 & 8.221 & 0.001 \\
2008 & 0.172 & 0.034 & 5.229 & 0.001 & 2014 & 0.339 & 0.038 & 9.042 & 0.001 \\
2009 & 0.169 & 0.036 & 4.793 & 0.002 & 2015 & 0.329 & 0.037 & 8.875 & 0.001 \\
\hline
\end{tabular}

Table 4. Changes of Moran's I scatter map of innovation output of prefectural cities in China in 2004 and 2015.

\begin{tabular}{|c|c|c|c|}
\hline \multirow{3}{*}{$\mathrm{I}$} & Lower & $\mathrm{HL}-\mathrm{LL}_{\mathrm{t}+1}$ & Taiyuan, Dongying, Guiyang \\
\hline & \multirow{2}{*}{ Higher } & $\mathrm{LH}-\mathrm{HH}_{\mathrm{t}+1}$ & Yangzhou, Zhenjiang, Taizhou, Jinhua, Nantong \\
\hline & & LL-HL $L_{t+1}$ & Xuzhou, Wuhu \\
\hline \multirow{3}{*}{ II } & Lower both & $\mathrm{HH}-\mathrm{LL}_{\mathrm{t}+1}$ & Lianyungang, Huaian, Suqian, Yancheng, Quanzhou \\
\hline & High \& Low & $\mathrm{LH}-\mathrm{HL}_{\mathrm{t}+1}$ & Anshan \\
\hline & Low \& High & $\mathrm{HL}-\mathrm{LH}_{\mathrm{t}+1}$ & Dongying \\
\hline \multirow{3}{*}{ III } & Lower & $\mathrm{LH}-\mathrm{LL}_{\mathrm{t}+1}$ & $\begin{array}{l}\text { Mudanjiang, Songyuan, Fuyang, Benxi, Liaoyang, Jinzhou, } \\
\text { Yingkou, Xiaogan, Yueyang, Yiyang, Xiangtan, Zhuzhou, Loudi, } \\
\text { Jieyang, Chaozhou }\end{array}$ \\
\hline & \multirow[b]{2}{*}{ Higher } & $\mathrm{HL}-\mathrm{HH}_{\mathrm{t}+1}$ & Nanjing, Hangzhou, Ningbo, Fuzhou, Xiamen, Lanzhu \\
\hline & & LL-LH ${ }_{t+1}$ & $\begin{array}{l}\text { Weinan, Baoji, Xianyang, Shangqiu, Shangluo, Hanzhou, } \\
\text { Tongling, Sanming, Longyan }\end{array}$ \\
\hline
\end{tabular}

cities change from low-level cities to high-level cities are cities in the Yangtze River Delta, Fujian and some cities in Shaanxi Province, which indicates that the spatial distribution of innovation output in this region is further optimized with the improvement of technology level and the balanced development among regions. The cities that are in or around the cities with opposite changes in innovation level are mostly inland cities, while the cities in Northeast China and $\mathrm{Hu}$ nan Province are mostly. The most common type of co-directional change is self and adjacent cities, which indicates that the spatial structure of innovation activities has a locking effect [7]. The three patents have different requirements for technological innovation capability and different spatial organizational structures. The spillover effect between regions promotes the development of urban innovation capability in different directions.

\section{Empirical Analysis of Influencing Factors of Innovation Output}

\subsection{Selection of Variables and Data Sources}

Innovation output is influenced by many factors, referring to previous literature 
[8] [9] [10] [12] [13] [14], considering the availability of data. This paper holds that infrastructure construction, investment in fixed assets, degree of economic extroversion, human capital, economic basis, fiscal policy and educational level are the main factors affecting innovation output. Among them, the number of Internet users is used to represent infrastructure construction; the actual amount of foreign direct investment (fdi) is used to represent the degree of economic extroversion in Prefecture-level cities; the research, technical services and geological exploration personnel (hcc) are used to reflect human capital; and the economic basis of prefecture-level cities is measured by the gross industrial output (inds) above the scale. The proportion of science education expenditure to financial expenditure (srip) is used to represent financial policy support, and the number of special teachers (edu) is used to reflect the impact of education level on innovation output, and the above six variables are the main indicators. This paper predicts that fixed asset investment (ffais) is a negative indicator. In this paper, based on the year of 2003, the formula for calculating positive index is $X^{*}=\left(X-X_{\min }\right) /\left(X_{\max }-X_{\min }\right)$, negative index $X^{*}=\left(X_{\max }-X\right) /\left(X_{\max }-X_{\min }\right)$. The data used in this paper are all from the "Urban Statistical Yearbook" over the years. The missing data are processed by arithmetic average method.

\subsection{Regression Modeling and Result Analysis}

The above Moran's I shows that innovation output has obvious spatial heterogeneity and spatial dependence at the level of $1 \%$, which leads to inconsistency in the results of common panel regression. In order to eliminate the errors of OLS model results, this paper adopts spatial panel data regression model based on maximum likelihood estimation method, and obtains the regression results of eliminating errors [15]. Spatial lag model, also known as spatial autocorrelation model, explores the endogenous interaction effect. Spatial error model includes the interaction effect of error terms. Because spatial Durbin model can solve the problem of spatial autocorrelation of error terms in spatial error model, it has been paid attention by academia. Based on LM and Housman test, this paper chooses fixed effect spatial lag model and fixed effect spatial Durbin model, and compares the least square method with spatial panel, and combines static panel with dynamic spatial panel to deeply explore the influencing factors of innovation output.

The expression of space lag effect is as follows:

$$
\begin{aligned}
Y_{i t}= & a+\rho W Y_{i t}+\beta_{1} \text { net }_{i t}+\beta_{2} \text { ffais }_{i t}+\beta_{3} \text { fdi }_{i t} \text { hcc }_{i t} \\
& +\beta_{4} \text { hcc }_{i t}+\beta_{5} \text { inds }_{i t}+\beta_{6} \operatorname{srip}_{i t}+\beta_{7} \text { edu }_{i t}+\mu+\varepsilon_{i t}
\end{aligned}
$$

The expression of the spatial Durbin model is

$$
\begin{aligned}
Y_{i t}= & a+\rho W Y_{i t}+\beta_{1} \text { net }_{i t}+\beta_{2} \text { ffais }_{i t}+\beta_{3} \text { fdi }_{i t} \text { hcc }_{i t}+\beta_{4} \text { hcc }_{i t} \\
& +\beta_{5} \text { inds }_{i t}+\beta_{6} \text { srip }_{i t}+\beta_{7} \text { edu }_{i t}+c W \text { srip }_{i t}+\mu+\varepsilon_{i t}
\end{aligned}
$$

Among them, $W$ is the spatial weight matrix of $n \times n, p$ is the spatial autoregressive coefficient, $\beta$ is the regressive coefficient of explanatory variables, $\mu$ is 
the observed individual effect, $c$ is the regressive coefficient of explaining the spatial lag term of variables, and $\varepsilon_{i t}$ is the error term of normal distribution.

The regression results are shown in Table 5 and Table 6 . Table 5 is the result of static spatial panel regression, column 2 is the panel data regression of random effects, column 3 and column 4 are the spatial lag model of fixed effects and spatial Durbin model respectively. Except for fiscal policy support, OLS regression was significantly positively correlated at a significant level of $1 \%$. Among them, human capital is the most important factor affecting innovation output, with a coefficient of 0.317 , which shows that when other explanatory variables remain unchanged, human capital increases by $1 \%$ and innovation output by $0.317 \%$. The contribution rate of industrial base to innovation output is second only to human capital. With other explanatory variables unchanged, for every $1 \%$ increase in industrial base, innovation output increased by $0.204 \%$. It also

Table 5. Regression analysis of influencing factors of innovation output spatial panel of prefecture-level cities.

\begin{tabular}{|c|c|c|c|c|}
\hline & (1) & (2) & (3) & (4) \\
\hline & OLS & SLM & SDM & Dynamic Spatial SDM \\
\hline \multirow{2}{*}{ net } & $0.030^{\star * \star}$ & $0.031^{* * *}$ & $0.030^{* * *}$ & $0.030^{* * *}$ \\
\hline & $(0.000)$ & $(0.000)$ & $(0.000)$ & $(0.000)$ \\
\hline \multirow{2}{*}{ ffais } & $0.056^{\star * *}$ & $0.037^{\star * \star}$ & $0.035^{* * *}$ & $0.027^{\star * *}$ \\
\hline & $(0.000)$ & $(0.000)$ & $(0.000)$ & $(0.000)$ \\
\hline \multirow{2}{*}{ fdi } & $0.045^{* * *}$ & $0.024^{* * *}$ & $0.024^{* * *}$ & $0.015^{\star *}$ \\
\hline & $(0.000)$ & $(0.002)$ & $(0.002)$ & $(0.045)$ \\
\hline \multirow{2}{*}{ hcc } & $0.317^{* * *}$ & $0.322^{* * *}$ & $0.324^{* * *}$ & $0.311^{* * *}$ \\
\hline & $(0.000)$ & $(0.000)$ & $(0.000)$ & $(0.000)$ \\
\hline \multirow{2}{*}{ inds } & $0.204^{* * *}$ & $0.184^{* * *}$ & $0.181^{* * *}$ & $0.174^{* * *}$ \\
\hline & $(0.000)$ & $(0.000)$ & $(0.000)$ & $(0.000)$ \\
\hline \multirow{2}{*}{ srip } & $8.86 \mathrm{E}-05$ & -0.007 & $-0.017^{\star \star}$ & -0.010 \\
\hline & $(0.990)$ & $(0.289)$ & $(0.023)$ & $(0.218)$ \\
\hline \multirow{2}{*}{ edu } & $0.037^{* * *}$ & $0.037^{\star * *}$ & $0.035^{\star * *}$ & $0.032^{\star * *}$ \\
\hline & $(0.000)$ & $(0.000)$ & $(0.000)$ & $(0.000)$ \\
\hline \multirow{2}{*}{ L.Wp } & & & & $0.208^{\star * *}$ \\
\hline & & & & $(0.000)$ \\
\hline \multirow{2}{*}{$\rho$} & & $0.211^{* * *}$ & $0.211^{\star * *}$ & $0.0605^{*}$ \\
\hline & & $(0.000)$ & $(0.000)$ & $(0.083)$ \\
\hline \multirow{2}{*}{$\alpha$} & $-0.055^{\star * *}$ & & & \\
\hline & $(0.000)$ & & & \\
\hline Obs & 3420 & 3420 & 3420 & \\
\hline
\end{tabular}

Note: 1) “*”, “**” and “***” are significant at the levels of $10 \%, 5 \%$ and $1 \%$ respectively; 2 ) The values in parentheses are the test $P$ values. 
Table 6. Empirical research on spatial effect of innovation output of prefectural cities in china based on dynamic Durbin model.

\begin{tabular}{|c|c|c|c|c|c|c|}
\hline & \multicolumn{3}{|c|}{ Short term effect } & \multicolumn{3}{|c|}{ Long term effect } \\
\hline & Direct & Indirect & Total & Direct & Indirect & Total \\
\hline \multirow{2}{*}{ net } & $0.030^{* * *}$ & 0.002 & $0.031^{\star * *}$ & $0.030^{* * *}$ & $0.010^{\star * *}$ & $0.040^{\star * *}$ \\
\hline & $(0.000)$ & $(0.126)$ & $(0.000)$ & $(0.000)$ & $(0.000)$ & $(0.000)$ \\
\hline \multirow{2}{*}{ ffais } & $0.028^{\star * *}$ & 0.002 & $0.030^{\star * *}$ & $0.028^{* * *}$ & $0.009^{* * *}$ & $0.038^{\star * \star}$ \\
\hline & $(0.000)$ & $(0.141)$ & $(0.000)$ & $(0.000)$ & $(0.000)$ & $(0.000)$ \\
\hline \multirow{2}{*}{ fdi } & $0.016^{\star *}$ & 0.001 & $0.017^{\star \star}$ & $0.016^{* *}$ & $0.005^{*}$ & $0.021^{* *}$ \\
\hline & $(0.033)$ & $(0.226)$ & $(0.033)$ & $(0.033)$ & $(0.045)$ & $(0.033)$ \\
\hline \multirow{2}{*}{ hcc } & $0.311^{\star * *}$ & 0.019 & $0.331^{\star * *}$ & $0.316^{* * *}$ & $0.107^{\star * *}$ & $0.423^{\star * *}$ \\
\hline & $(0.000)$ & $(0.124)$ & $(0.000)$ & $(0.000)$ & $(0.000)$ & $(0.000)$ \\
\hline \multirow{2}{*}{ inds } & $0.175^{\star * *}$ & 0.011 & $0.186^{* * *}$ & $0.178^{\star * *}$ & $0.060^{* * *}$ & $0.238^{\star * *}$ \\
\hline & $(0.000)$ & $(0.122)$ & $(0.000)$ & $(0.000)$ & $(0.000)$ & $(0.000)$ \\
\hline \multirow{2}{*}{ srip } & -0.010 & $0.023^{* *}$ & 0.013 & -0.009 & $0.025^{\star \star}$ & 0.016 \\
\hline & $(0.199)$ & $(0.016)$ & $(0.191)$ & $(0.240)$ & $(0.021)$ & $(0.189)$ \\
\hline \multirow{2}{*}{ edu } & $0.033^{* * *}$ & 0.002 & $0.035^{* * *}$ & $0.033^{\star * *}$ & $0.011^{* * *}$ & $0.044^{* * *}$ \\
\hline & $(0.000)$ & $(0.142)$ & $(0.007)$ & $(0.000)$ & $(0.000)$ & $(0.000)$ \\
\hline Obs & 3135 & 3135 & 3135 & 3135 & 3135 & 3135 \\
\hline
\end{tabular}

Note: 1) “*”, “**” and “***” are significant at the levels of $10 \%, 5 \%$ and $1 \%$ respectively; 2 ) The values in parentheses are the test $P$ values.

proves that innovation is a process of input and output, and the quality and quantity of innovation input largely determine the difference of innovation ability. When introducing spatial autocorrelation and spatial dependence into the model, the importance of human capital and industrial base has not changed. Human capital is the main participant of innovation activities and the essential input factor of innovation activities. Many innovative outputs come from industrial production activities. Solid industrial foundation provides a continuous impetus for innovative activities. It can also increase innovation support and provide material basis for innovative activities. Fixed assets investment can greatly promote economic development, but a large part of fixed assets investment in real estate development. The hot real estate market attracts more capital investment and reduces financial support for innovation activities. The empirical results show that there is a negative relationship between fixed asset investment and innovation output, which also confirms that the fixed asset investment proposed in the literature [16] [17] has a significant squeezing effect on innovation activities. The empirical results show that education level, infrastructure and economic extroversion can improve innovation output capacity. The improvement of education level can provide high-quality talents for research institutions and innovative enterprises, and improve the utilization efficiency of innovative output by utilizing the "production-learning-research" innovation chain. The 
improvement of infrastructure, especially the popularization of Internet, breaks through the limitation of geographical location to a certain extent, provides more learning opportunities, and speeds up the dissemination of knowledge and technology among cities. On the one hand, economic openness can enhance the connection with international advanced technology and knowledge, integrate the differentiated technology and knowledge carried by large-scale foreign direct investment with local innovation activities, shorten the exploration time, and introduce and re-innovate with higher efficiency and faster speed. The spatial autoregressive coefficients of SLM and SDM models with fixed effects were tested at the level of $1 \%$ and positive. This shows that there is an obvious spatial spillover effect in China's innovation output, that is, the innovation output of a city is closely related to that of the surrounding cities and changes in the same direction. In other words, the increase of innovation output of a city will lead to the improvement of innovation ability of surrounding cities, while the enhancement of innovation ability of surrounding cities will promote the increase of innovation output of the city.

Referring to the previous literature, this paper will lag behind two periods. The results show that the spatial autoregressive coefficient of the dynamic panel SDM model is positive, and it passes the significance test at the level of $10 \%$. Human capital, industrial base, education level and infrastructure construction all pass the significant level test of $1 \%$, and the spatial lag of innovation input in surrounding cities has a significant positive correlation with innovation output. Foreign direct investment passes the significant level test of 5\%, fixed assets investment passes the significant level test of $1 \%$, and its impact on innovation output is significant positive correlation. The impact of spatial lag on innovation output of this city is significantly negative. The empirical results show that the investment of the surrounding cities in infrastructure construction, economic openness, human capital, industrial foundation and education level has a significant role in promoting the city's innovation output. Among them, the input of human capital has the most obvious impact on the city's innovation output. With other factors unchanged, every $1 \%$ increase of human capital input in the surrounding cities will promote the innovation output of the prefecture-level cities to increase by $0.317 \%$. Policy factors can include providing preferential policies for innovative enterprises and increasing support for innovative activities. In OLS and SLM models with fixed effects, the impact of science and education expenditure on innovation output is not significant.

The results of dynamic spatial SDM model show that no matter how long it takes, the direct effect is the main driving force to promote the development of innovation output. Specifically, the direct effect of innovation input is the most significant in the short term. It can also be said that a city's input and innovation factors will promote the innovation output of the city in the short term, and have a weak impact on the innovation output of the surrounding cities. The significant level of long-term direct and indirect effects is improved, and the impact of innovation input on innovation output is enhanced. The regression coeffi- 
cient of long-term direct effects is generally larger than that of dynamic spatial SDM model. This is because the direct effect includes "feedback effect". Taking human capital as an example, when other factors remain unchanged, the innovation output of a city increases by $0.316 \%$ for every $1 \%$ increase in human capital, and $0.107 \%$ for the surrounding cities. And the results show that the indirect effect of science and education expenditure is significantly positive, which indicates that the science and education expenditure of surrounding cities has a significant role in promoting the innovation output of this city, and the impact on innovation output is enhanced.

\section{Conclusions}

With the implementation of innovation-driven development strategy, governments at all levels attach importance to the creation of an innovative environment and the support of innovative industries. However, the development of information technology has greatly promoted the regional flow of innovation factors and changed the pattern of innovation output in China. Therefore, this paper uses invention patents, utility models and design patents to represent innovation output, and comprehensively grasps the pattern of innovation output based on regional differences, spatial evolution of regional differences and spatial autocorrelation of innovation output. The results show that China's innovation ability is in the stage of rapid improvement, with the fastest growth in the central region. However, China's innovation output is mainly concentrated in the municipalities directly under the Central Government and provincial capitals in the eastern coastal areas, as well as in the provincial capitals in the western areas. Regional differences are the main factors of innovation capability differences in China. Innovation output is mainly concentrated in a few central cities, which is highly consistent with the distribution pattern of major urban agglomerations in China. However, with the change of time, the spatial organizational structure among cities is becoming richer and richer. Cities with high innovative output play a coordinating and driving role. The innovation difference between cities decreases, and the Theil index shows a significant downward trend. The spatial autocorrelation degree shows an upward trend, which indicates that knowledge spillover effect is more obvious. Most of the cities in the Yangtze River Delta and Pearl River Delta as well as the surrounding cities of the capital of Shaanxi Province have migrated. The most common phenomenon is that the cities and the surrounding cities show the same level of change, with obvious path dependence and lock-in effect.

Based on the spatial static panel data and the spatial dynamic panel data model from 2004 to 2015, this paper explores the influencing factors of innovation output at different levels. The results show that when considering urban autocorrelation and urban dependence, the impact of fixed assets investment and industrial basic factors on innovation output decreases, and the proportion of infrastructure construction, human capital, science and education and the re- 
gression coefficient of education level increase, which are all important factors affecting innovation output, of which human capital is one of the most important factors. And the industrial base has the most obvious effect on the improvement of innovation ability. The factor input and innovation output of the surrounding cities have a significant impact on the city's innovation ability. The long-term effect of technological innovation capability of cities and surrounding cities is greater than the short-term effect, and the direct effect includes feedback effect, so the regression coefficient of each influencing factor is higher than that of dynamic spatial panel.

As China enters the new normal and emphasizes sustainable economic development, innovation becomes an important driving force to improve resource utilization efficiency and industrial transformation and upgrading. Although the spatial spillover effect is becoming more and more obvious, the major urban agglomerations in the eastern region and the provincial capitals in the central and western regions are still the highlands of China's innovation capability. In order to improve the innovative ability and optimize the spatial pattern of innovative output of Chinese cities, firstly, we should pay attention to the cultivation of human capital, provide continuous supply of high-quality talents for the innovation chain of "production-learning-research"; consolidate the economic foundation, and give full play to the two-way promotion of economic development and innovative activities. Secondly, we should establish a diversified urban collaboration mechanism, improve the quantity, quality and level of innovation interaction among cities, accelerate the cross-regional flow of innovation elements and optimize the allocation of innovation resources. Finally, we should cultivate regional innovation growth poles and play a coordinating and driving role for the surrounding cities.

Innovation output has other indicators such as patent and new product output value, which is limited by the availability of data. In this paper, only three kinds of patent data are used to characterize innovation output, which has certain limitations. At the same time, because 285 cities do not all have adjacent relationships, it is unstable to use only 0 - 1 matrix for spatial weight matrix regression. It is hoped that the range of indicators and regression methods can be continuously supplemented in the future, and the matrix can be constructed from multiple perspectives.

\section{Conflicts of Interest}

The author declares no conflicts of interest regarding the publication of this paper.

\section{References}

[1] Schumpeter, J.A. (1934) The Theory of Economic Development. Harvard University Press, Cambridge.

[2] (2016) The National Innovation-Driven Development Strategy Outline Was Issued and Proposed to Build a World-Leading Scientific and Technological Innovation 
Nation by 2050. E-Government, No. 6, 79.

[3] Wang, C.Y. and Zhang, C. (2013) Geographic Concentration and Spatial Dependence-Time Space Model of Provincial Innovation in China. Studies in Science of Science, 31, 780-789.

[4] Fan, L.N. (2005) Spatial Distribution and Contribution Factors of Patents in China. Journal of Beijing Normal University Social Science Edition, No. 2, 138-145.

[5] Li, Z.G., Tang, S.K., Liang, X.Y. and Wu, L.G. (2006) Research on the Spatial Distribution of Chinese Innovation Output: Spatial Econometrics Analysis Based on Province-Level Patent Data. Science of Science and Management of S\&T, No. 8, 64-71.

[6] Chen, J. and Chen, N. (2012) Analysis on Spatial Characteristic of Patent Distribution and Factors of Regional Innovation Potential of China. Journal of University of Science and Technology of China, 42, 252-258.

[7] Wang, C.Y and Zhang, C. (2014) Spatial Temporal Pattern of Prefecture-Level Innovation Output in China: An Investigation Using the ESDA. Scientia Geographica Sinica, 34, 1438-1444.

[8] He, S.H., Du, D.B., Jiao, M.Q. and Lin, Y. (2017) Spatial Pattern of Urban Innovation Capability and Impact Factor Analysis in China. Scientia Geographica Sinica, 37, 1014-1022.

[9] Zhang, Y.M. and Li, K. (2008) Research on the Spatial Dependence of Chinese Province-Level Innovation Output. Studies in Science of Science, No. 3, 659-665.

[10] Jiang, T.Y. (2009) Spatial Differentiation and Its Influencing Factors Regional Innovation Output in Zhengjiang Province. Geographical Research, 33, 1825-1836.

[11] Lesage, J.P. and Pace, R.K. (2009) Introduction to Spatial Econometrics. CRC Press, Boca Raton, 513-514. https://doi.org/10.1201/9781420064254

[12] Wang, J.S., Yan, Y. and Hu, S.H. (2017) Spatial Pattern and Determinants of Chinese Urban Innovative Capabilities Based on Spatial Panel Data Model. Scientia Geographica Sinica, 37, 11-18.

[13] Wen, H. and Hu, B. (2014) A Spatial Econometric Study on the Influence Factor of Provincial Cultural and Creative Industries Development in China. Economic Geography, 34, 101-107.

[14] Hu, X.Q. and Yang, Q. (2017) Spatial Spillover Effects among FDI, Energy Efficiency and Independent Innovation. Collected Essays on Finance and Economics, No. 9, 105-112.

[15] Anselin, L. (1988) Spatial Econometrics: Methods and Models. Kluwer Academic Publishers, Boston. https://doi.org/10.1007/978-94-015-7799-1

[16] Zhang, J., Yang, L.X. and Xin, F. (2016) Does Real Estate Impede China's Innovation?-An Explanation Based on the Loan Structure of the Financial System. Management World, No. 5, 64-80.

[17] Yu, Y.Z. and Zhang, S.H. (2017) Ruban Housing Prices, Purchase Restriction Policy and Technological Innovation. China Industrial Economics, No. 6, 98-116. 